\title{
Identification and characterization of a POU transcription factor in the cotton bollworm, Helicoverpa armigera Tian-Yi Zhang1,2 and Wei-Hua Xu*1
}

\author{
Address: ${ }^{1}$ State Key Laboratory of Biocontrol, School of Life Sciences, Sun Yat-Sen (Zhongshan) University, Guangzhou 510275, PR China and \\ ${ }^{2}$ Current address : Department of Ophthalmology, Harvard Medical School and Massachusetts Eye and Ear Infirmary, Boston, Massachusettes, USA \\ Email: Tian-Yi Zhang - Tianyi_Zhang@meei.harvard.edu; Wei-Hua Xu* - xuweihua@mail.sysu.edu.cn \\ * Corresponding author
}

Published: 25 March 2009

BMC Molecular Biology 2009, 10:25 doi:10.1 186/147|-2199-10-25

This article is available from: http://www.biomedcentral.com/147I-2199//0/25

(C) 2009 Zhang and Xu; licensee BioMed Central Ltd.

This is an Open Access article distributed under the terms of the Creative Commons Attribution License (http://creativecommons.org/licenses/by/2.0), which permits unrestricted use, distribution, and reproduction in any medium, provided the original work is properly cited.
Received: 26 September 2008

Accepted: 25 March 2009

\begin{abstract}
Background: The POU family genes containing the POU domain are common in vertebrates and invertebrates and play critical roles in cell-type-specific gene expression and cell fate determination.

Results: Har-POU, a new member of the POU gene family, was cloned from the suboesophageal ganglion of Helicoverpa armigera (Har), and its potential functions in the development of the central nervous system (CNS) were analyzed. Southern blot analysis suggests that a single copy of this gene is present in the $\mathrm{H}$. armigera haploid genome. Har-POU mRNA is distributed widely in various tissues and expressed highly in the CNS, salivary gland, and trachea. In vitro-translated Har-POU specifically bound canonical octamer motifs on the promoter of diapause hormone and pheromone biosynthesis activating neuropeptide (DH-PBAN) gene in $\mathrm{H}$. armigera. Expression of the Har-POU gene is markedly higher in the CNS of nondiapause-destined pupae than in diapause-destined pupae. Expression of the Har-POU gene in diapausing pupae was upregulated quickly by injection of ecdysone.
\end{abstract}

Conclusion: Har-POU may respond to ecdysone and bind to the promoter of DH-PBAN gene to regulate pupal development in $\mathrm{H}$. armigera.

\section{Background}

The development of many insects is regulated by environmental signals such as photoperiod, temperature, humidity, and nutrients. The central nervous system (CNS) of insects accepts these environmental stimuli and transduces them into endogenous chemical messengers (neuropeptides or hormones) in the neuroendocrine organs [1]. The neuropeptides and hormones induce insect developmental arrest at a certain stage: embryonic, larval, pupal, or adult. The programmed arrest of development is called diapause. In Bombyx mori (Bom), embryonic diapause is caused by a neuropeptide diapause hormone (DH), which is secreted from the suboesophageal gan- glion (SG) and acts on the developing ovaries of the pharate adult to induce the laying of diapause eggs in the next generation [2]. Interestingly, neuropeptide pheromone biosynthesis activating peptide (PBAN), which can stimulate the pheromone gland of female adults to secrete sex pheromone to attract male adults for mating in Lepidoptera, is also encoded by DH cDNA [3]. Thus, the DH cDNA and gene also are referred as the DH-PBAN cDNA and DH-PBAN gene, respectively [4]. DH-PBAN cDNAs have been cloned from a number of Lepidoptera species.

The DH-PBAN gene was first cloned in B. mori [4]. The transcription factor POU-M2, a member of the POU fam- 
ily of genes, interacts specifically with the promoter of the Bom-DH-PBAN gene and regulates its transcription [5]. Initially, the transcription factors Pit, Oct, and Unc (POU) were found to possess a conserved DNA binding region of approximate 160 amino acids, and the conserved DNA binding region was then designated as the POU domain [6]. The POU domain consists of two subdomains, the POU-specific domain and a homeobox domain. The POU family genes containing the POU domain are common in vertebrates and invertebrates and play critical roles in celltype-specific gene expression and cell fate determination [7]. Based on the variations of POU-homeobox domains, they are divided into six classes (POU-I -VI), with POUIII the largest class $[8,9]$.

One of the main functions of POU-III members in mammals is to regulate the development of the CNS and neuroendocrine system and the expression of some neurohormones [10]. In insects, POU-III members have been cloned from Drosophila melanogaster (drifter) and Bombyx mori (POU-M1/M2). drifter from D. melanogaster was first identified as a neuron-specific regulator binding the C element of the dopa decarboxylase gene [11]. Later, drifter was found to be involved in multiple important developmental events: differentiation and migration of tracheal cells and neurons [12-14], cell fate determination of Drosophila imaginal discs [15], and neuronal lineage and wiring [16-19]. POU-M1 from B. mori was cloned from the silk gland and was found to bind the SC element of the sericin-1 gene and regulate its transcription [20]. POU-M2 is an isoform of POU-M1 and regulates expression of the B. mori DH-PBAN gene, an important neuropeptide related to development [5].

Recently, a second DH-PBAN gene from the pupal diapause species Helicoverpa armigera (Har) (Lepidoptera: Noctuidae) was cloned and showed a potential binding site for the POU in the promoter sequences [21]. Although the DH-PBAN gene is involved in controlling egg diapause in $B$. mori and pupal diapause in $H$. armigera, the respective mechanisms might be different, and the two temporal patterns are significantly different. The DHPBAN mRNA content in B. mori pupae destined to lay diapause eggs is 2.7 times higher than that of pupae destined to lay nondiapause eggs [22]. The DH-PBAN mRNA content in diapause-type pupae of $H$. armigera is significantly lower than that of nondiapause-type pupae [23]. Therefore, we want to clarify whether the transcription factor POU is involved in regulating DH-PBAN expression to control pupal diapause in $H$. armigera.

Here we report the cloning and characterization of a cDNA encoding POU in H. armigera (Har-POU) as well as analysis of its genome copy, tissue distribution, and DNA binding activity. Furthermore, we show that developmen- tal expression of the Har-POU gene is much higher in the CNS of nondiapause pupae than that of diapause-type pupae. Thus, expression of the Har-DH-PBAN gene is closely correlated with the response to the Har-POU transcription factor.

\section{Results \\ Isolation and sequence analysis of Har-POU}

By using degenerate primers POUF and POUR based on the nucleotide sequences conserved between $B$. mori and D. melanogaster, PCR amplification yielded a product of approximately $900 \mathrm{bp}$. The amino acid sequence encoded by this cDNA fragment shows $96.7 \%$ and $54.5 \%$ similarity with the corresponding regions of POU from $B$. mori and $D$. melanogaster, respectively. To obtain the full-length POU CDNA, 5' - and 3'-RACE were performed with specific primers based on the sequence of the 900-bp cDNA fragment. Approximately $370 \mathrm{bp}$ at $5^{\prime}$-end and $1500 \mathrm{bp}$ at 3 'end were amplified by PCR, and the two fragments were subcloned into vectors and sequenced. The full-length cDNA is 2455 bp, including a 204-bp 5' untranslated region, 1056-bp open-reading frame, and a 1195-bp 3' untranslated region (Fig. 1). This sequence has been submitted to GenBank (accession number: AY513764).

The Har-POU cDNA encodes 351 amino acids containing a conserved class POU-III-specific and homeobox domain located on amino acids 153-296. Alignment shows that the POU domain of Har-POU is the same as drifter in Drosophila and POU-M1/M2 in B. mori (Fig. 2A), and only two amino acids differ from that of APH-1, another arthropod POU-III gene of Artemia franciscana [24]. The POU domain also has high similarity with other POU-III genes in C. elegans and mammals (data not shown). The similarity at the $\mathrm{N}$-terminal of Har-POU is $78.1 \%, 93.5 \%$, and $29.0 \%$; and at C-terminal is $92.5 \%, 92.5 \%$, and $61.5 \%$ to POU-M1, POU-M2, and drifter, respectively (Fig. 2B).

\section{Har-POU copy number in $\mathrm{H}$. armigera haploid genome}

The copy number of the POU gene in the H. armigera genome was determined by Southern blotting. The cDNA fragment corresponding to the $\mathrm{N}$-terminal and POU domain of Har-POU was used as a probe. As shown in Fig. $3 \mathrm{~A}$, only a single band of 5-6 kb was detected in the genomic DNA digested with Hind III or EcoR I. Thus, HarPOU is probably encoded by a single gene in the $H$. armigera genome.

\section{Tissue distribution of Har-POU mRNA}

Tissue distribution of Har-POU mRNA was detected by northern blot analysis. A band of about $2.5 \mathrm{~kb}$ was detected from the brain, SG, trachea, and salivary gland, indicating that the characterized cDNA cloned by RACE represents the full-length mRNA (Fig. 3B). The tissue dis- 
ACGCGGGGAGTCCGCTCCGTGCTGCCGTCGCGCACGCACGCGCATGTCGCTCGCTGTTGTATTCGGTGA TGT GAGGTGGCCCCCGCCGCTGCCGCAGCGCCGCGCGACTAACGCGCTTTTTTCGCGACCGAGTAAGCCAG TTGAAGGCTCGAGAGCCTTCGAGCCGGCAAGACGCCGTCCACCGTGGATCTGAGGTACGGCGCCATG GCG 210 GCG ACC ACG TAC ATG CCC GCC GAC ATG GAC CTG GGC GAC ATC GGC GGG TAC CAT

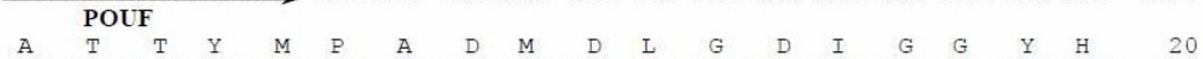
GCA GCG TCG CCG CGC AGT GCC GAG CCC GCC GAC ATG AAG TAC CAG CAC GGG CTG 318 $\begin{array}{lllllllllllllllllllll}\text { A } & \text { A } & S & P & R & S & A & E & P & A & D & M & K & Y & \& & H & G & L & 38\end{array}$ CAC GCG GGC GGC TCG CCG TCC CCG GGC GCG CCC GTG CTC AAC CCG TGG ACG TCG 372

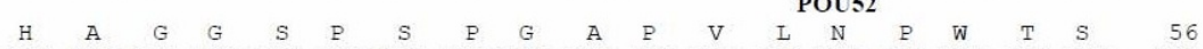
CTG CCG CCG GCC GAC CCC TGG GCC ATG CAC CAG CAC CAC GCG CAC GCG CAC CAG 426 $\begin{array}{lllllllllllllllllllll}\text { L } & P & P & \text { A } & \text { D } & \text { P } & \text { W } & \text { A } & \text { M } & \text { H } & \& & \text { H } & \text { H } & \text { A } & \text { H } & \text { A } & \text { H } & \& & & 74\end{array}$ CCC GAC GTG AAG CCG CCG CCG GCG CCG CAC GAG CAC CGC CAC CTG CAG CAC GGC 480 $\begin{array}{lllllllllllllllllll}P & D & V & \text { K } & \text { P } & \text { P } & \text { P } & \text { A } & \text { P } & \text { H } & \text { E } & \text { H } & \text { R } & \text { H } & \text { I } & \& & H & G & 92\end{array}$ GGC TGG CAC GCG CCC GTG GTG TCG CCG CAC TAC GGC GCC GGC ACG CCC GTG GCA 534 $\begin{array}{lllllllllllllllllllll}G & W & H & A & P & \text { V } & \text { V } & S & P & \text { H } & Y & G & \text { A } & G & \text { T } & \text { P } & \text { V } & \text { A } & 110\end{array}$ CTG CAC GGC GGC TAC CCC ATG CCC ATG CAC CAG CAC CAC ATG CTG CGC GAC ATC 588 $\begin{array}{lllllllllllllllllll}I & H & G & G & Y & P & M & P & M & H & \& & H & H & M & L & R & D & I & 128\end{array}$ CAG CCC TCG CCG CAC CCG CTG CAC CAC CAC GCC ATG GAG CGC GAG CCG CCC GAG 642 $\begin{array}{lllllllllllllllllllll}Q & P & S & P & H & P & L & H & H & H & A & M & E & R & E & P & P & E & 146\end{array}$ GAG GAC ACG CCC ACC AGC GAC GAC CTC GAG GCC TTC GCC AAG CAG TTC AAG CAG 696 $\begin{array}{llllllllllllllllllll}\mathrm{E} & \mathrm{D} & \mathrm{T} & \mathrm{P} & \mathrm{T} & \mathrm{S} & \boldsymbol{D} & \boldsymbol{D} & \boldsymbol{L} & \boldsymbol{E} & \boldsymbol{A} & \boldsymbol{F} & \boldsymbol{A} & \boldsymbol{K} & \boldsymbol{Q} & \boldsymbol{F} & \boldsymbol{K} & \boldsymbol{Q} & 164\end{array}$ CGC CGC ATC AAG CTG GGC TTC ACG CAG GCC GAC GTG GGC CTG GCG CTC GGC ACE 750 $\begin{array}{lllllllllllllllllll}R & R & I & K & I & G & F & T & \& & A & D & V & G & I & A & I & G & T & 182\end{array}$ $\stackrel{\text { CTC TAC GGC AAT GTG TTC TCC }}{\longrightarrow}$ AAG ACC ACC ATC TGC CGG TTC GAG GCG CTG CAG 804 $\begin{array}{lllllllllllllllllll}I & Y & G & N & V & F & S & \& & T & T & I & C & R & F & E & A & I & \& & 200\end{array}$ CTC AGT TTt AAA AAT ATG TGC AAG TTG AAA CCG CTG CTC CAG AAG TGG CTG GAG 858 $\begin{array}{lllllllllllllllllll}I & S & F & K & N & M & C & K & I & K & P & I & I & \mathcal{E} & K & W & I & E & 218\end{array}$ GAA GCC GAT TCG ACG ACG GGG AGT CCC ACG AGT ATC GAT AAA ATA GCC GCA CAA 912 $\begin{array}{lllllllllllllllllll}\boldsymbol{E} & \boldsymbol{A} & D & S & T & T & G & S & P & T & S & I & D & K & I & A & A & \boldsymbol{Q} & 236 \\ \end{array}$ \begin{tabular}{|lllllllllllllllllll}
\hline $\boldsymbol{G}$ & $\boldsymbol{R}$ & $\boldsymbol{K}$ & $\boldsymbol{R}$ & $\boldsymbol{K}$ & $\boldsymbol{K}$ & $\boldsymbol{R}$ & $\boldsymbol{T}$ & $\boldsymbol{S}$ & $\boldsymbol{I}$ & $\boldsymbol{E}$ & $\boldsymbol{V}$ & $\boldsymbol{S}$ & $\boldsymbol{V}$ & $\boldsymbol{K}$ & $\boldsymbol{G}$ & $\boldsymbol{A}$ & $\boldsymbol{I}$ & 254
\end{tabular} GAG CAG CAC TTC CAC AAG CAG CCC AAG CCG ICG GCG CAG GAG ATC ACG TCG CTG 1020

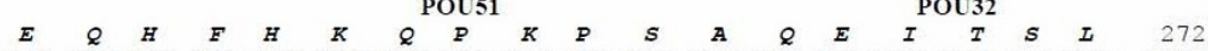

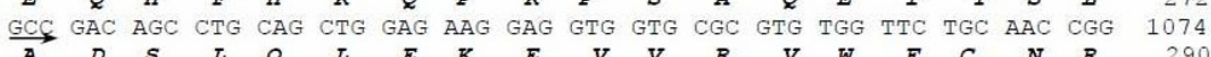
CGG CAG AAG GAG AAG CGC ATG ACG CCG CCC AAC ACG CTG GGC AAC GAG ATG ATG 1128

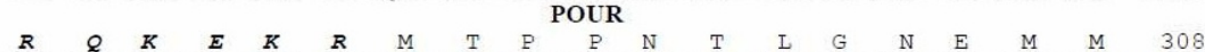
GAG GGC ATG GGC CAC GGC CAC TAC GGG CAC GGC GAG GTG CAC GGC AGT CCG CTG 1182 $\begin{array}{llllllllllllllllllll}E & G & M & G & H & G & H & Y & G & H & G & E & V & H & G & S & P & \text { L } & 326\end{array}$ CAG CAC TCG CAC TCG CCG CCC GGG CTG TCG CCG CAG CAC GGG CTG CCG GCG GGC 1236 $\begin{array}{llllllllllllllllllllllll}Q & H & S & H & S & P & P & G & L & S & P & \& & H & G & I & P & A & G & 344\end{array}$ GCG CAC ACG CTG GCC GCG CAC TAA CAGTTCGCCCCGTGGGCGCCGCCGCGGCCCTACTACTCG 1299 A $\mathrm{H}$ T $\mathrm{I}$ A $\mathrm{A}$ H GAGCCTCACTAGCGCCGACTAGTCGCCGCGCCCGCGGGATACCGACCGTGTACATAGCGCCGCGCGCCCGG 1370 ACGTGCCCGCGGCGCAAGT GACGGCCGCGCTTGTACATACCT GT GCGCGAGCCGGACTACACCCGAACGCT 1441 ACGTTTAAGTTGTTCTTTATAATTTCAGTGAAGTCATTGATTAATTATGTGAGTAATGTTAAGATCGAAGC 1512 CAGTAATCGTTTATACTTTATCGAAACGCCGAGGTTCGGAGTGATCGCCGATACGTTTAGCTAGATAGTCT 1583 AATTGATAAATAAGAGCTTAAATCGGAGGTGGATCCCGGCGTCGCTCGCGCCTCGCCGGCGGCCGCGGCCG 1654 CAGCATCGTCGTGCGGTAAGTACGGCGACATTACACACTCACGAGTAGCACTGTAGCGCGCGTACCGAGCG 1725 CACACTGAGCGCATGCCGAGCGCACCGCGTACTT GTCGCACGCGAAGCCGCGACCTGCGAGTCGCGCGAGC 1796 CGCGAGGCCGCTCCGGCGAGGAGTGCGAAGCACTATTCAGTTTTGTAAAGGACGATTTCATCGAATTTATT 1867 TATAGATATTACAAATTAACGATGTTCATAAATGCCTACCTGTCAGTAGGGAGTCATTGTGGTGTGGAATA 1938 AATTTAAATTGTTGCTATTACTGTAAATTTATGATTAGTGATGAGGAAGAGTAAAAAATATGAATCGGGTC 2009 GAAGCTTCGTTTTGTAAGGGAATACGAGTGAGTCAATAGGTGCAATTTTTATTTTAAGTGTTTAATGAAAC 2080 GATCCGAAT GT GA GAGCAATCATGTACGTAGTAAGCCAAGAGCGAGTAGCGCGACGCGCCGCGCGCTCTGT 2151 TGGTGTTGCGAGCGCGCGTACGTGCGGCGCGCTACTCGCGCGACAACGCGCGACACGCACTCGACGCACAC 2222 CTAGCTCCCACTACATAATTTATTCAAATTATTATTAAAAGGATGCAGACACGATGCCAAAATGGTTTTAT 2293 TCCTGTTTTTTACTTGTTTTGTTGTTTTTTCGTTTGTATGTATTTGTGGCCAATCTTGGTACTTAATACTT 2364 GTAAAAATAGGTATTTTTTCTATATAAAATAATGTACCTACGACGTATATGATGATATATATTAAAAAAGT 2435 TCTTTATAGAAATTGAAATCCAAAAAAAAAAAAAAAAAAAAAAAAAAAAAAA

\section{Figure I}

Nucleotide and amino acid sequences of a cDNA encoding Har-POU. The potential nuclear localization signal sequence is shown in the rectangle, and the POU-specific and homeobox domains are shown in bold italics. Arrows below the nucleotide sequences represent the position of the different synthetic primers used in PCR. Degenerate primers are POUF (5'CCATGGCGGCGAC(C/G)AC(C/G)TA(C/T)ATG-3') and POUR (5'-CAGCGTGTTGGG(C/T)GG(C/T)GTCAT-3'). This sequence has been submitted to GenBank (accession number: AY5I3764). 

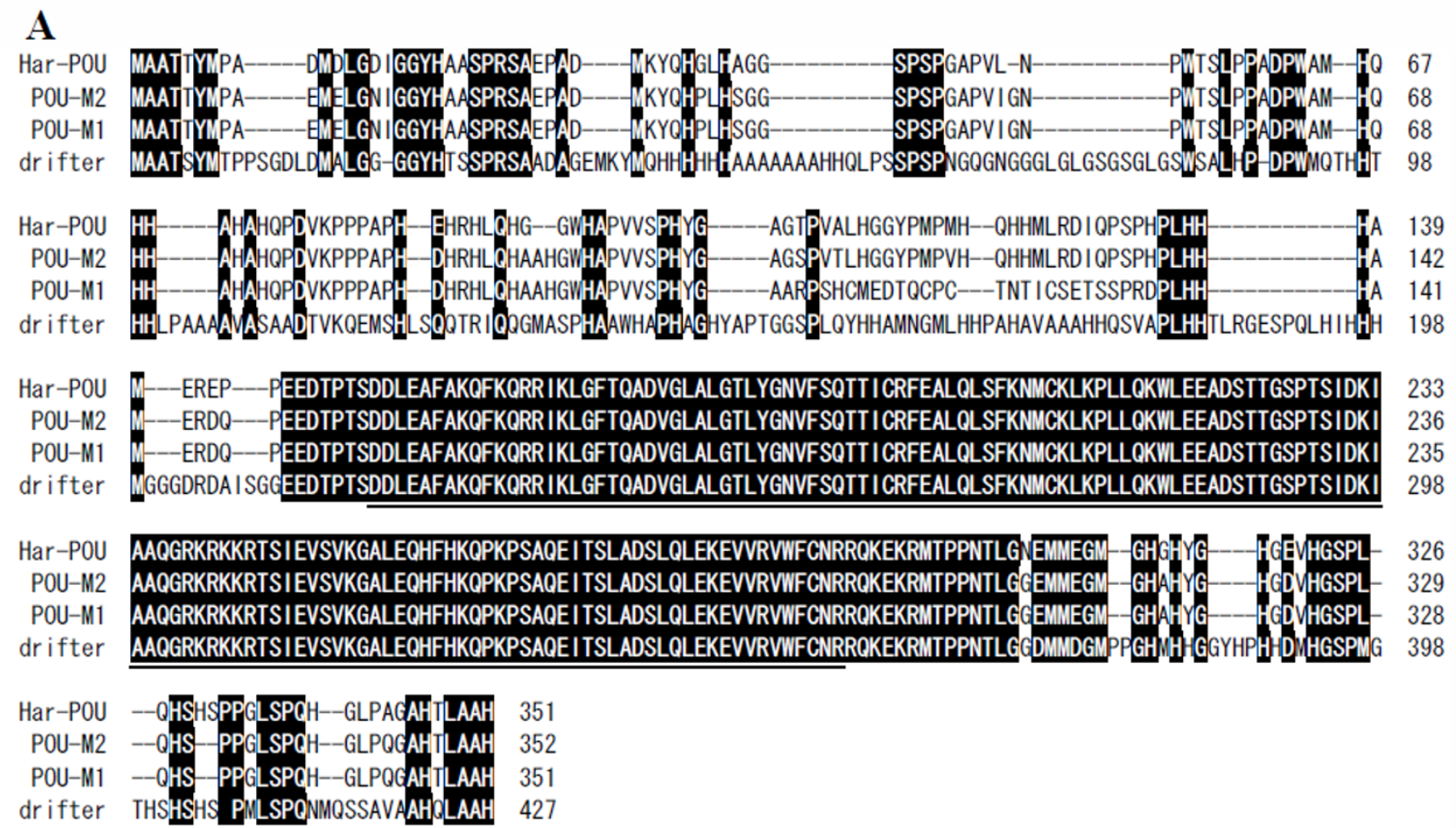

B

Har-POU AGTPVALHGGYPMPHQHHMLRDIQPSPH
POU-M2 AGSPVTLHGGYPMPHQHHMLRDIQPSPH
POU-M1 AARPSHCMEDTQCPCTNTICSETSSPR-D

Figure 2

Sequence alignment of Har-POU with POU-MI/-M2 from B. mori and Drifter from D. melanogaster. (A) The POU-specific and homeobox domains are underlined. Identical residues are shaded in black. The numbers on the right indicate the amino acids of each protein. (B) Amino acid sequence similarities of 28 amino acids from residue 106 to residue 133 of POUs. The highly conserved residues $(\geq 67 \%)$ are shaded in black.

tribution of Har-POU is consistent with that of drifter, which is mainly expressed in migrating neurons and tracheal cells in Drosophila [12].

\section{Nuclear localization of Har-POU}

A basic sequence (GRKRKKRT) preceding helix 1 of the homeodomain was demonstrated to be a nuclear localization sequence in Oct- 6 , a member of the mammalian POU-III class [25]. This sequence is also conserved in invertebrate POU-III proteins including the Har-POU (Fig. 2A). To confirm whether Har-POU localizes to the nuclei efficiently, the eGFP-fused Har-POU was transfected into Hela cells. The eGFP-Har-POU exclusively localized to nuclei that were marked by DAPI (Fig. 4).

\section{DNA binding activities of Har-POU}

Most of the POU proteins bind specifically to an octamer motif (ATGNAAAT). Three probes containing an octamer motif from insect genes were used in the EMSA assays: SA from the Bom-sericin promoter [26], S1 from the BomDH-PBAN promoter [5], and $\mathrm{H} 1$ from the Har-DH-PBAN promoter [21]. The in vitro translated Har-POU protein bound all three probes efficiently, and the binding could be competed by 40-fold unlabeled H1 (Fig. 5).

\section{Har-POU expression is related to pupal diapause}

Previous studies have demonstrated that expression of the Har-DH-PBAN gene is high in nondiapause-destined pupal individuals, but low in diapause-destined ones. 

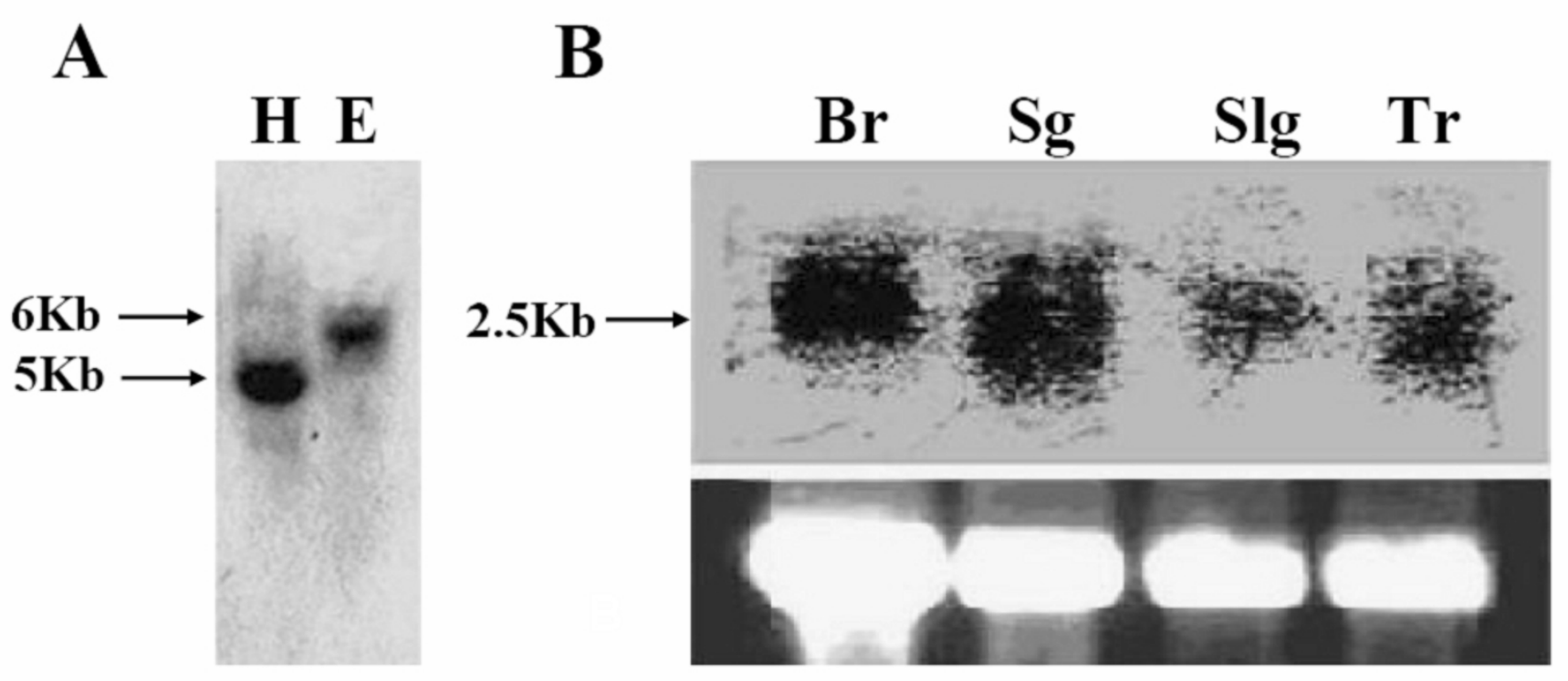

Figure 3

Southern and northern blot analyses. (A) Southern analysis. $10 \mu \mathrm{g}$ of $H$. armigera genomic DNA was digested with Hind III (lane $\mathrm{H}$ ) and EcoR I (lane E), and hybridized with ${ }^{32}$ P-labeled Har-POU cDNA fragment. The sizes of the hybridizing fragments are indicated on the left. (B) Northern analysis. Total RNA $(25 \mu \mathrm{g})$ was loaded on each lane, and the bottom panel shows the amount of ribosomal RNA loaded per lane (ethidium staining) as a control for loading variation. Br, brain; Sg, suboesophageal ganglion; Slg, salivary gland; Tr, trachea.

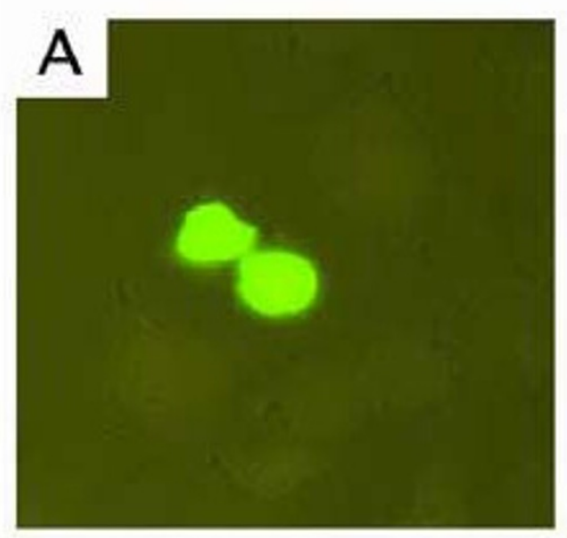

\section{GFP}

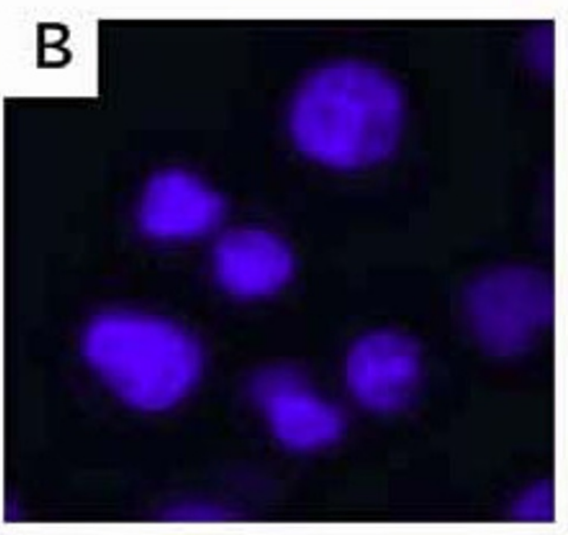

DAPI

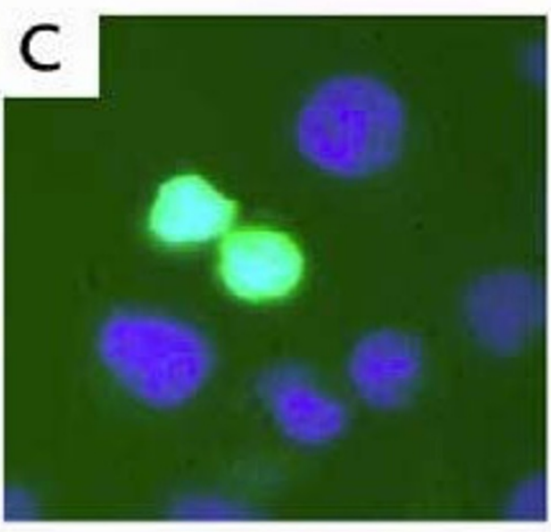

Merge

Figure 4

Nuclear localization of Har-POU. The eGFP-fused Har-POU was transfected into Hela cells. (A) The expression of HarPOU-eGFP; (B) DAPI staining to show the nuclei of the cells. (C) Overlapping of (A) and (B) to show that Har-POU-eGFP is located exclusively in the nuclei. 

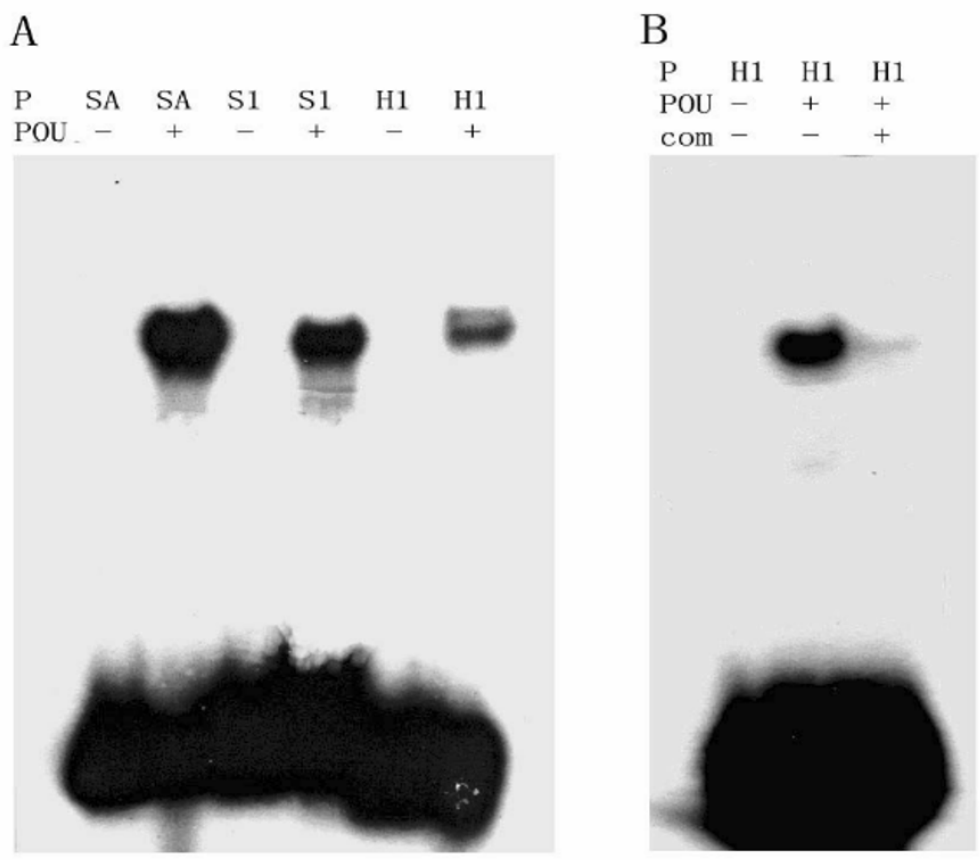

\section{Figure 5}

Detection of Har-POU binding activity by electrophoresis mobility shift assay. (A) Har-POU binds with probes SA, $\mathrm{SI}$, and HI. (B) 40-fold of cold HI specifically competes the biding of Har-POU and HI. The sequences of the probes SA, SI, and $\mathrm{HI}$ are described in materials and methods. $\mathrm{P}$, probe; POU, Har-POU protein expressed in vitro; com, cold $\mathrm{HI}$ as a competitor.

Since we showed that Har-POU bound to the Har-DHPBAN promoter, we investigated the developmental patterns of Har-POU mRNA in the two types of pupal individuals using RT-PCR combined with Southern blot. HarPOU mRNA content in nondiapause-destined individuals was robust from day 0 to day 10 , whereas the Har-POU mRNA level of diapause-destined individuals at the corresponding time points was constantly low (Fig. 6A). The results show a close relationship between the gene expression of Har-POU and Har-DH-PBAN. Further, we investigated the developmental changes in Har-POU mRNA when pupal diapause was broken by injection of ecdysone. Har-POU mRNA in diapausing pupae increased to a high level 6 hours after injection and remained at consistently high levels from pupal development to the adult stage (Fig. 6B).

\section{Discussion and Conclusion}

The studies presented here show: 1) cloning and characterization of Har-POU, a POU-III class gene in $H$. armig$e r a ; 2)$ that only a single copy of Har-POU exists in the $H$. armigera haploid genome; 3) Har-POU is expressed in various tissues and highly expressed in nervous, tracheal, and secretory tissues; 4) Har-POU localizes to the nuclei and binds three different probes containing octamer motifs; 5) Har-POU mRNA is highly expressed in developing individuals (nondiapause-destined pupae) and expressed at low levels in the programmed development-arrest individuals (diapause-destined pupae); 6) when pupal diapause is broken by injection of ecdysone, Har-POU gene expression immediately responds to restart development. These data imply that Har-POU's structure and function are conserved with POU-M1/-M2 in B. mori and drifter in D. melanogaster.

Usually, there is only one POU-III class gene in each invertebrate species, including D. melanogaster [11], C. elegans [8], crustacean A. franciscana [24], and the urochordate $O$. dioica at the invertebrate-vertebrate transition [9]. From the complete genome of several species, it has been shown that there are four POU-III genes in Human and mouse, but only one gene in invertebrates, including Drosophila and C. elegans [8]. Our results also show that there is only one copy of Har-POU in $H$. armigera. Interestingly, there are two isoforms of POU-III class genes in B. mori: POU$\mathrm{M} 1$ and $-\mathrm{M} 2$, which were cloned in Japanese and Chinese 

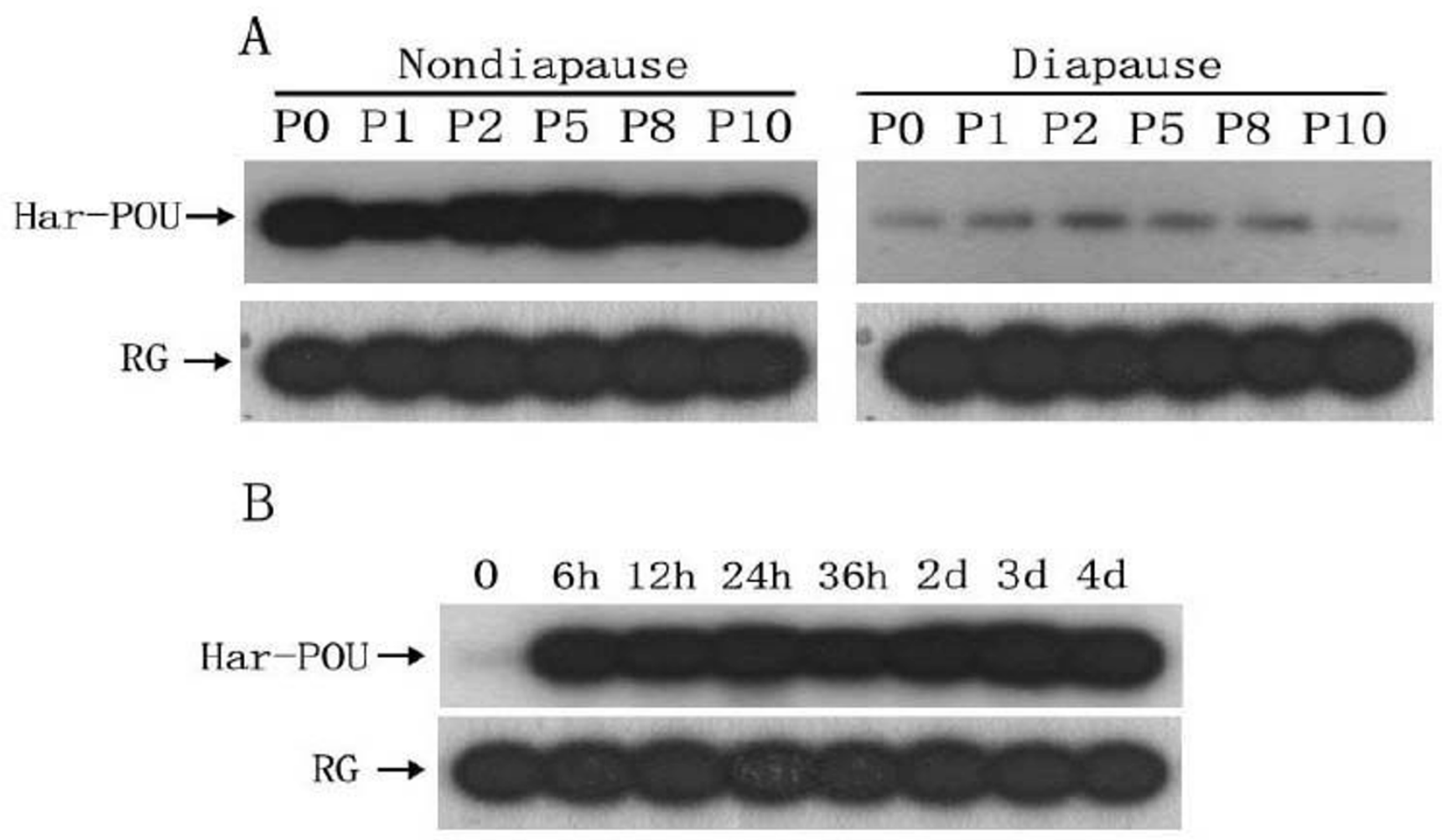

Figure 6

Developmental expression of Har-POU mRNA detected by semi-quantitative RT-PCR and Southern hybridization. (A) Expression of Har-POU mRNA during pupal development of nondiapause-destined and diapause-destined individuals. Abbreviations: P0-PI0, 0-I0 days after pupation; RG, rabbit globin. (B) Expression of Har-POU mRNA in diapausing pupae. Abbreviations $\mathrm{h}$ and $\mathrm{d}$ represent hours and days after injection of ecdysone to diapausing pupa.

B. mori, respectively $[5,20]$. These two proteins differ by a 28-amino acid sequence at their $\mathrm{N}$-terminal (from residue 106 to residue 133) (Fig. 2B). This difference is produced by the insertion and loss of nucleotide acids, possible evidence of a polymorphism in B. mori strains. Since both $B$. mori and $H$. armigera belong to Lepidoptera, the similarity of the protein sequences can tell us which one is the main isoform in B. mori. As shown in Fig. 2B, 25 of the 28 amino acids of Har-POU are the same as that of POU-M2, and only 4 amino acids are conserved between Har-POU and POU-M1. Thus, we propose that POU-M2 may be the main isoform in Lepidoptera.

Diapause insects provide a good model for studying development and metabolism. H. armigera is a pupal diapause species, and its nervous system development stops after pupation. drifter in Drosophila has multiple functions in neuronal migration, lineage, and wiring [12,16-19]. Our results show that Har-POU expression is robust in the CNS of nondiapause pupae but very low in diapause-destined ones, suggesting that Har-POU has important functions in the development and remodeling of the $H$. armigera nervous system. The expression pattern of HarPOU is almost identical to that of Har-DH-PBAN. It is known that DH terminates diapause and promotes continuous development in Heliothis virescens, H. armigera, and Helicoverpa assulta $[23,27,28]$. Therefore, we propose that Har-POU might play a key role in regulating development by changing the Har-DH-PBAN transcript. In addition, Har-POU responds to the injection of ecdysone, well-known to regulate genes related to insect development [29-31]; thus it will be interesting to know whether Har-POU is its direct target.

\section{Methods \\ Animals}

$H$. armigera larvae were reared on an artificial diet at 22$23^{\circ} \mathrm{C}, 60 \%$ relative humidity, under a photoperiod of L14:D10 (light:dark) to produce nondiapause pupae, and at $20-21^{\circ} \mathrm{C}$ with a cycle of L10:D14 to induce diapausetype pupae.

To break diapause, $5 \mu \mathrm{l}$ of a solution containing $1 \mu \mathrm{g} 20$ hydroxyecdysone (Sigma) or $5 \mu$ l distilled water as control 
was injected into $H$. armigera diapausing pupae through a fine glass capillary. The trachea, salivary gland from $6^{\text {th }}$ instar larval stage, and brain, SG or brain-SG complex from pupal stage, were dissected in insect saline containing $0.75 \% \mathrm{NaCl}$ and stored at $-70^{\circ} \mathrm{C}$ for RNA extraction.

\section{Cloning and sequence analysis}

Total RNA was prepared from the brain-SG complexes of day-8 pupae (pharate adult). RNA extraction, RNA quantification, and reverse transcription were the same as described previously [23]. Two degenerate primers POUF (5'-CCATGGCGGCGAC(C/G)AC(C/G)TA(C/T)ATG-3') and POUR (5'-CAGCGTGTTGGG(C/T)GG(C/T)GTCAT3 ') designed based on the highly conserved regions of $B$. mori POU-M2 and D. melanogaster drifter were used for PCR amplification under the following conditions: three cycles of $94^{\circ} \mathrm{C}, 45 \mathrm{~s} ; 45^{\circ} \mathrm{C}, 1 \mathrm{~min} ; 72^{\circ} \mathrm{C}, 45 \mathrm{~s}$, and then 30 cycles of $94^{\circ} \mathrm{C}, 30 \mathrm{~s} ; 50^{\circ} \mathrm{C}, 1 \mathrm{~min} ; 72^{\circ} \mathrm{C}, 45 \mathrm{~s}$.

To obtain the full-length Har-POU cDNA, rapid amplification of cDNA ends (RACE) was used. Specific primers (POU5-1 and POU5-2 for 5'-RACE, and POU3-1 and POU3-2 for 3'-RACE) were designed according to the sequence obtained from the internal amplification above. RACE reactions were performed with a SMART ${ }^{\mathrm{TM}}$ RACE kit (Clontech) according to standard protocol.

The PCR products were separated on a $1.2 \%$ agarose gel and ligated into a T-vector (TaKaRa). The recombinant DNA was transformed into E. coli, XL1-Blue competent cells. Positive clones were selected, and the isolated recombinant DNA was sequenced by TaKaRa Co. (Dalian, China).

\section{Semi-quantitative RT-PCR}

Total RNA was prepared from the brain-SG of pupae. Total RNA from one brain-SG (about $1.5 \mu \mathrm{g}$ ) was reversetranscribed. To normalize the efficiency of RNA reverse transcription in each reaction, $0.1 \mathrm{ng}$ of rabbit globin (RG) mRNA (Promega) was added as external standard [22]. The primers and programs for PCR were the same as above, except the number of cycles was decreased from 30 to 20. The PCR products were electrophoresed on a $1.2 \%$ agarose gel and transferred onto a Hybond $\mathrm{N}^{+}$Nylon membrane (Amersham). The Har-POU cDNA was labeled with $[\alpha-32 P]-d C T P$ as a probe using a random primed DNA labeling kit (TaKaRa). Nylon membrane was prehybridized for $4 \mathrm{~h}$ followed by addition of the radiolabeled probe for $18 \mathrm{~h}$ at $42^{\circ} \mathrm{C}$ in $5 \times \operatorname{SSPE}(1 \times \operatorname{SSPE}=180 \mathrm{mM}$ $\mathrm{NaCl}, 10 \mathrm{mM}$ sodium phosphate, pH 7.7, 1 mM EDTA) containing $50 \%$ formamide, $5 \times$ Denhardt's solution, $0.1 \%$ SDS, and $100 \mu \mathrm{g} / \mathrm{ml}$ salmon sperm DNA. After hybridization, the membrane was washed with $0.2 \times$ SSPE at $45^{\circ} \mathrm{C}$ and finally exposed to the X-ray film for $20 \mathrm{~h}$ at $70^{\circ} \mathrm{C}$.

\section{Northern and Southern blot analyses}

For northern analysis, $25 \mu \mathrm{g}$ of total RNA was separated on a $1.2 \%$ agarose gel containing $0.22 \mathrm{M}$ formaldehyde and ethidium bromide, and subsequently blotted onto Hybond $\mathrm{N}^{+}$membrane.

Genomic DNA was isolated from the adult body of $H$. armigera using the procedure of Xu et al. [4]. $10 \mu \mathrm{g}$ of highmolecular-weight genomic DNA was prepared, digested with restriction endonucleases, electrophoresed on a $1.0 \%$ agarose gel, and transferred to Hybond $\mathrm{N}^{+}$membrane. The hybridization probe and conditions and signal detection were the same as above.

\section{Construction of expression system}

The open reading frame of Har-POU was amplified by the primers POU-EF (5'-CGGGATCCCCATGGCGGCGACCACGTACATG-3') and POU-ER (5'-CCCAAGCTTTTAGTGCGCGGCCAGCGTGTGC-3'). The underlined sequences correspond to Bam $\mathrm{H}$ I and Hind III restriction sites. The PCR products were purified, digested by BamH I and Hind III, and cloned into pBluescript KS (+) or pEGFP-C1 (Clontech) plasmid. The recombinant plasmids were named T7-Har-POU and eGFP-Har-POU.

\section{In vitro translation and electrophoresis mobility shift assay (EMSA)}

T7-POU plasmid DNA ( $1 \mu \mathrm{g})$ was used as a template for in vitro translation in the TNT Quick Coupled Transcription/Translation System (Promega) containing $40 \mu \mathrm{l}$ of TNT T7 Quick Master Mix, $1 \mu$ l of methionine ( $1 \mathrm{mM})$, and $8 \mu$ l of distilled water. The reaction was allowed to proceed at $30^{\circ} \mathrm{C}$ for $1.5 \mathrm{~h}$, and $2 \mu \mathrm{l}$ of translation product was then used for the EMSA assay.

The probes used in EMSA were SA (5'-CTTGTATACATTGTTTGCAC AAATGTTTG-3') at -81 to -109 of Bom-sericin promoter [25], S1 (5'-CCCCTCATTTACATACATCCCCGTCCGAC-3') at -80 to -52 of the Bom-DH-PBAN promoter [5], and H1 (5'-TCCCTGATTTACATAAGAT TTCCATTCG-3') at -64 to -37 of the Har-DH-PBAN promoter [21].

In general, $10 \mathrm{fmol}$ of ${ }^{32} \mathrm{P}$-labeled probe was incubated with $2 \mu \mathrm{l}$ of translated product for $30 \mathrm{~min}$ at $27^{\circ} \mathrm{C}$ in a 20 $\mu \mathrm{l}$ reaction mixture containing $10 \mathrm{mM}$ HEPES- $^{+}(\mathrm{pH}$ 7.9), $10 \%$ glycerol, $50 \mathrm{mM} \mathrm{KCl}, 4 \mathrm{mM} \mathrm{MgCl}_{2}, 1 \mathrm{mM}$ DTT, $0.5 \mathrm{mg} / \mathrm{ml}$ BSA, $0.1 \mathrm{mM}$ PMSF and $1 \mu \mathrm{g}$ of poly (dI-dC) (Pharmacia). Reaction mixtures were loaded onto a $5 \%$ native polyacrylamide gel and electrophoresed in $1 \times \mathrm{TBE}$ buffer. After electrophoresis, the gel was dried and subjected to autoradiography in the presence of an intensifying screen at $-70^{\circ} \mathrm{C}$ for $16 \mathrm{~h}$. Competition assay was performed by preincubating the reactions with the speci- 
fied amount of excess unlabeled probes for $10 \mathrm{~min}$ before the addition of labeled probes.

\section{Intracellular localization assay}

Human cervical cancer cell line Hela was cultured in Dulbecco's modified Eagle's medium supplemented with $10 \%$ fetal bovine serum (FBS) and penicillin $(100 \mu / \mathrm{ml}) /$ streptomycin $(0.1 \mathrm{mg} / \mathrm{ml})$ at $37^{\circ} \mathrm{C}$ in $5 \% \mathrm{CO}_{2}$. Transfections of cells were performed using Lipofectamine 2000 (Invitrogen) according to manufacturer's instructions. Each co-transfection was performed in duplicate. The cell nuclei were counter-stained with DAPI and visualized with an inverse fluorescence microscope (Olympus IX70).

\section{Authors' contributions}

TZ carried out all of experiments and wrote the manuscript. WX conceived the project, supervised the experiments and co-wrote the manuscript. All authors read and approved the final manuscript.

\section{Acknowledgements}

This study was supported by a Grant-in-Aid for the Natural Scientific Foundation (307300 I4) from the National Natural Science Foundation of China, and the Major State Basic Research Developmental Program

(2006CB I0200I) from the Ministry of Science and Technology of China.

\section{References}

I. Denlinger DL, Yocum GD, Rinehart JL: Hormonal control of diapause. In Comprehensive molecular insect science Volume 3. Edited by: Gilbert LI, latrou K, Gill SS. Amsterdam: Elsevier Press; 2005:6 I 5-650.

2. Yamashita O: Diapause hormone of the silkworm, Bombyx mori: structure, gene expression and function. J Insect Physiol 1996, 42:669-679.

3. Sato Y, Oguchi M, Menjo N, Imai K, Saito H, Ikeda M, Isobe M, Yamashita O: Precursor polyprotein for multiple neuropeptides secreted from the suboesophageal ganglion of the silkworm Bombyx mori: characterization of the cDNA encoding the diapause hormone precursor and identification of additional peptides. Proc Natl Acad Sci USA 1993, 90:3251-3255.

4. Xu WH, Sato Y, Ikeda M, Yamashita O: Molecular characterization of the gene encoding the precursor protein of diapause hormone and pheromone biosynthesis activating neuropeptide of the silkworm, Bombyx mori and its distribution in some insects. Biochim Biophys Acta 1995, I 26 I:83-89.

5. Zhang TY, Kang L, Zhang ZF, Xu WH: Identification of a POU factor involved in regulating the neuron-specific expression of the gene encoding diapause hormone and pheromone biosynthesis-activating neuropeptide in Bombyx mori. Biochem J 2004, 380:255-263.

6. Herr W, Sturm RA, Clerc RG, Corcoran LM, Baltimore D, Sharp PA, Ingraham HA, Rosenfeld MG, Finney M, Ruvkun G, Horvitz HR: The POU domain: a large conserved region in the mammalian pit-I, oct-I, oct-2, and Caenorhabditis elegans unc-86 gene products. Genes Dev 1988, 2:1513-1516.

7. Ryan AK, Rosenfeld MG: POU domain family values: flexibility, partnerships, and developmental codes. Genes Dev 1997, I I:I207-I225.

8. Burglin TR, Ruvkun G: Regulation of ectodermal and excretory function by the $C$. elegans POU homeobox gene ceh-6. Development 200I, I 28:779-790.

9. Cupit PM, Lennard ML, Hikima J, Warr GW, Cunningham C: Characterization of two POU transcription factor family members from the urochordate Oikopleura dioica. Gene 2006, 383: $1-11$.

10. Andersen B, Rosenfeld MG: POU domain factors in the neuroendocrine system: lessons from developmental biology provide insights into human disease. Endocr Rev 200 I, 22:2-35.
II. Johnson WA, Hirsh J: Binding of a Drosophila POU-domain protein to a sequence element regulating gene expression in specific dopaminergic neurons. Nature 1990, 343:467-470.

12. Anderson MG, Perkins GL, Chittick P, Shrigley RJ, Johnson WA: Drifter, a Drosophila POU-domain transcription factor, is required for correct differentiation and migration of tracheal cells and midline glia. Genes Dev 1995, 9:123-137.

13. Anderson MG, Certel SJ, Certel K, Lee T, Montell DJ, Johnson WA: Function of the Drosophila POU domain transcription factor drifter as an upstream regulator of breathless receptor tyrosine kinase expression in developing trachea. Development 1996, I22:4169-4I78.

14. Zelzer E, Shilo BZ: Interaction between the bHLH-PAS protein Trachealess and the POU-domain protein Drifter, specifies tracheal cell fates. Mech Dev 2000, 91:163-73.

I5. Certel K, Hudson A, Carroll SB, Johnson WA: Restricted patterning of vestigial expression in Drosophila wing imaginal discs requires synergistic activation by both Mad and the drifter POU domain transcription factor. Development 2000, | 27:3173-3183.

16. Ma Y, Certel K, Gao Y, Niemitz E, Mosher J, Mukherjee A, Mutsuddi M, Huseinovic N, Crews ST, Johnson WA, Nambu JR: Functional interactions between Drosophila bHLH/PAS, Sox, and POU transcription factors regulate CNS midline expression of the slit gene. J Neurosci 2000, 20:4596-4605.

17. Inbal A, Levanon D, Salzberg A: Multiple roles for u-turn/ventral veinless in the development of Drosophila PNS. Development 2003, I 30:2467-2478.

18. Komiyama T, Johnson WA, Luo L, Jefferis GS: From lineage to wiring specificity. POU domain transcription factors control precise connections of Drosophila olfactory projection neurons. Cell 2003, I I 2: I57-167.

19. Certel SJ, Thor S: Specification of Drosophila motoneuron identity by the combinatorial action of POU and LIM-HD factors. Development 2004, I 3 I:5429-5439.

20. Fukuta M, Matsuno K, Hui CC, Nagata T, Takiya S, Xu PX, Ueno K, Suzuki Y: Molecular cloning of a POU domain-containing factor involved in the regulation of the Bombyx sericin-I gene. J Biol Chem 1993, 268: 1947|-19475.

21. Zhang TY, Sun JS, Kang L, Shen JL, Xu WH: Structural analysis and transcriptional regulation of the gene encoding diapause hormone and pheromone biosynthesis activating neuropeptide in the cotton bollworm, Helicoverpa armigera. Biochim Biophys Acta 2005, I 728:44-52.

22. Xu WH, Sato Y, Ikeda M, Yamashita O: Stage-dependent and temperature-controlled expression of the gene encoding the precursor protein of diapause hormone and pheromone biosynthesis activating neuropeptide in the silkworm, Bombyx mori. J Biol Chem 1995, 270:3804-3808.

23. Zhang TY, Sun JS, Zhang QR, Xu J, Jiang RJ, Xu WH: The diapause hormone-phermone biosynthesis activating neuropaptide gene of Helicoverpa armigera encodes multiple peptides that break, rather than induce, diapause. J Insect Physiol 2004, 50:547-554.

24. Chavez M, Landry C, Loret S, Muller M, Figueroa J, Peers B, RentierDelrue F, Rousseau GG, Krauskopf M, Martial JA: APH-I, a POU homeobox gene expressed in the salt gland of the crustacean Artemia franciscana. Mech Dev 1999, 87:207-2I2.

25. Sock E, Enderich J, Rosenfeld MG, Wegner M: Identification of the nuclear localization signal of the POU domain protein Tst-I/ Oct6. J Biol Chem 1996, 27I: I7512-17518.

26. Takiya S, Kokubo $H$, Suzuki $Y$ : Transcriptional regulatory elements in the upstream and intron of the fibroin gene bind three specific factors POU-MI, Bm Fkh and FMBP-I. Biochem J 1997, 32 I:645-653.

27. Zhao JY, Xu WH, Kang L: Functional analysis of a FXPRLamide neuropeptide in the pupal diapause of the oriental tobacco, Helicoverpa assulta (Lepidoptera: Noctuidae). Regul Peptides 2004, I | 8:25-3I.

28. Xu WH, Denlinger DL: Molecular characterization of prothoracicotr-opic hormone and diapause hormone in Heliothis virescens during diapause, and a new role for diapause hormone. Insect Molec Biol 2003, I 2:509-516.

29. Levine RB, Morton DB, Restifo LL: Remodeling of the insect nervous system. Curr Opi Neurobiol 1995, 5:28-35. 
30. Riddiford LM, Cherbas P, Truman JW: Ecdysone receptors and their biological actions. Vitam Horm 2000, 60: 1-73.

31. Zheng X, Wang J, Haerry TE, Wu AY, Martin J, O'Connor MB, Lee $\mathrm{CH}$, Lee $\mathrm{T}$ : TGF-beta signaling activates steroid hormone receptor expression during neuronal remodeling in the Drosophila brain. Cell 2003, I I 2:303-3 I5.

Publish with Bio Med Central and every scientist can read your work free of charge

"BioMed Central will be the most significant development for disseminating the results of biomedical research in our lifetime. " Sir Paul Nurse, Cancer Research UK

Your research papers will be:

- available free of charge to the entire biomedical community

- peer reviewed and published immediately upon acceptance

- cited in PubMed and archived on PubMed Central

- yours - you keep the copyright

Submit your manuscript here:

http://www.biomedcentral.com/info/publishing_adv.asp
BioMedcentral 